Tropelías. Revista de Teoría de la Literatura y Literatura Comparada, 23 (2015) 61 Fábulas, educación literaria y didáctica de los valores: Leo Lionni

\title{
FÁBULAS, EDUCACIÓN LITERARIA Y DIDÁCTICA DE LOS VALORES: LEO LIONNI
}

\author{
Ramón F. LLORENS GARCÍA \\ Universidad de Alicante \\ ramon.1lorens@ua.es
}

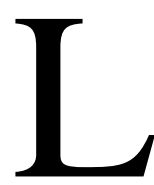
a literatura infantil y juvenil fue con frecuencia identificada con obras cuyo único objeto consistía en convertirse en simples transmisoras de enseñanzas; obras en las que los valores estéticos quedaban subordinados a los objetivos didácticos y «[...] al carecer de las virtualidades de la competencia estética, [contribuían] decididamente a inmovilizar -cuando no a pervertir- la creatividad de sus destinatarios». (Sánchez Corral, 1995: 4). Se acentuó esta concepción cuando las obras comenzaron a ir destinadas a prelectores o primeros lectores. Si bien es cierto que el componente didáctico-moralizante, fiel a la máxima horaciana del «instruir deleitando», había prevalecido en numerosas ocasiones sobre el texto literario hasta desvirtuarlo y convertirlo en un mero pretexto para la instrucción, la literatura infantil y juvenil ha logrado en la actualidad que su poder de seducción, al menos en una parte de su producción, se deba a la riqueza de matices literarios y no a los objetivos didácticos. Que ética y estética convivan, no quiere decir que la literatura esta esté obligada a transmitir valores sociales «si aumentara la atención dedicada a pensar que, al mismo tiempo, los libros sirven para aprender literariamente, la literatura infantil podría ser juzgada también desde los parámetros de su eficacia en esta tarea» (Colomer, 1999: 20).

La literatura infantil y juvenil contribuye a la formación literaria y humana de los lectores, al conocimiento de distintos tipos de manifestaciones artísticas, al desarrollo de su conciencia ética y de su pensamiento crítico, y no debería producirse el conflicto entre la dependencia de los fines moralizantes de la obra, su instrumentalización didáctica y su dimensión metafórica y simbólica. La educación literaria y la educación en valores no tienen por qué discordar, siempre que el valor estético prevalezca sobre cualquier otro. La literatura, dentro de su función educativa, transmite una serie de valores sociales, pero estos no deben empañar y debilitar el texto artístico. «[L]as lecturas no olvidan al lector y le transmiten ideología a través del placer, ensayando mecanismos discursivos que facilitan al lector la identificación con lo narrado» (Lluch, 2003: 129). Los valores sociales se encuentran a menudo en las obras de manera implícita y esta es la didáctica de los valores que debemos proponer desde la literatura. La transversalidad escolar corre el riesgo de convertirse en el siglo XXI, en la 
moralina decimonónica para niños, en aquellos textos escritos solamente para enseñar una moral (Llorens, 2000: 75). La línea fronteriza entre el didactismo y la función educativa de la literatura, tal vez se encuentre en la voluntad del escritor, en su compromiso poético, artístico y en su compromiso social, es lo que diferencia el panfleto de la obra de arte. Efectivamente «la altura ética de los contenidos no asegura su impregnación en los receptores si no conlleva una potencia expresiva que asegure el deleite lector» (Tejerina y Echevarría, 2007: 271). Profundizando en esta idea, si la literatura pierde su capacidad de suscitar el placer por la lectura, su facultad de connotar y de exigir una competencia específica para poder realizar múltiples lecturas, múltiples interpretaciones, se aleja de la literatura para convertirse en un libro de instrucción que puede responder a otros objetivos igualmente respetables y válidos, pero no relacionados con la adquisición y el desarrollo de la competencia literaria. «Sólo cuando nos cuenta historias emocionantes, se salta las recetas, rompe con los estereotipos y es capaz de construir personajes completos en todas sus dimensiones humanas, únicamente esa literatura aumenta nuestra conciencia, afirma nuestro juicio moral y nos ayuda a crecer interiormente» (Tejerina, 2000: 184). El objetivo de un docente de literatura debe ser contribuir a la formación literaria y humana de sus discentes, como hemos afirmado anteriormente, los valores van implícitos:

La buena literatura por sí misma nos lleva a la reflexión, y nos merece particular atención para este propósito de la educación en valores aquella literatura que posee una visión comprometida y crítica, la que plantea temas sociales conflictivos y dilemas morales con la necesaria complejidad y atractivo, máxime para unos lectores en formación que empiezan a enfrentarse a su libertad de elección, a su capacidad de decidir entre posiciones enfrentadas y, en definitiva, a construir su responsabilidad moral (Tejerina, 2008: 64).

En este papel que representa la literatura en la educación de valores estéticos y valores sociales, las fábulas han sido siempre un referente de literatura didáctica y han tenido desde sus orígenes también un receptor infantil. Se trataba de manifestaciones literarias breves, dialógicas, que, con frecuencia, tenían a animales como protagonistas, animales que hablaban, que razonaban, y que actuaban como humanos, al mismo tiempo que servían a los fabulistas para proyectar sus objetivos didácticos, políticos, y para dar pautas ejemplares de comportamiento moral. Las fábulas llegaban a los cultos y a los analfabetos, a adultos y a niños que se veían condicionados a realizar una lectura no unívoca:

\footnotetext{
Dans ces textes, le risque majeur serait de prendre les représentations pour des pratiques effectives et de considérer le texte de manière univoque. La fable peut être lue comme la métaphorisation d'un savoir social, elle renvoie à une autre manière de dire l'histoire et à une autre forme d'écriture de l'histoire. Raconter une fable en situation, c'est prendre le risque de l'histoire, c'est à dire de l'engagement. Dans sa partie narrative, la fable n'impose pas de sens, le corps de la fable ne signifie rien en soi, ce qui la laisse ouverte à de nombreuses interprétations en fonction du contexte où elle est utilisée. L'auditeur comme l'interprète ne sont pas libres de dire ou d'entendre n'importe quoi, ils ont des points d'appui dans le contexte du moment pour valider leur interprétation. Enoncé en situation, il signifie plus que ce qu'il dit littéralement (Charpentier, 2007: 145).
}

Las fábulas han estado presentes desde los orígenes de la historia literaria, aunque «nuestra idea de fábula procede, en realidad, de las colecciones de La Fontaine y sus continuadores a partir del siglo XVII, los cuales recogieron principalmente fábulas en que intervienen animales» (Rodríguez Adrados, 1979: 18-19). No se trataba de obras propiamente pertenecientes a la literatura infantil, pero los niños 
también eran sus receptores y las fábulas han formado parte de las lecturas educativas de los escolares. En una de las primeras obras españolas del siglo XIX que incluyó una selección de «trozos escogidos» para los niños de educación primaria, Alberto Lista, al recoger en su segundo tomo de lecturas poéticas las fábulas de Samaniego e Iriarte afirmó que era el género «más a propósito para la inteligencia de los niños» (Lista, 1859: v).

A lo largo de los siglos XIX, XX y XXI han seguido reeditándose en España las fábulas de Esopo, La Fontaine, Samaniego, Iriarte o Hartzenbusch y comenzaron a adquirir mayor relevancia las adaptaciones ejemplarizantes dirigidas a un destinatario infantil.

En las distintas propuestas literarias basadas en las fábulas, la aparición en el panorama de la literatura infantil de los años 60 de Leo Lionni, polifacético artista, diseñador gráfico y autor de álbumes ilustrados que se había dado a conocer con Pequeño azul, pequeño amarillo, se convirtió en un caso singular. Sus primeros títulos publicados en España por la editorial Lumen, llevaron traducciones de Ana María Matute (Nadarín, Frederick) o Esther Tusquets (El sueño de Matías).

Nos ocuparemos en este artículo de algunas de las interpretaciones que Frederick ofrece a los distintos tipos de lector, de su propuesta ética, de sus valores estéticos y sociales, y de obra paradigmática en el camino hacia una didáctica de los valores ${ }^{1}$.

El escritor de Amsterdam le aportó a la fábula un curso diferente, la actualizó al tiempo que la adaptaba a su época y la arropó con un nuevo género: el álbum ilustrado. No resultaba innovador que las fábulas fueran acompañadas por ilustraciones, pero sí la elección de una nueva manifestación artística, el álbum ilustrado, surgida en el siglo Xx. El álbum le resultó a Lionni el género adecuado para transmitir sus fábulas, las relaciones entre texto e ilustración le permitían transmitir los valores propios de la época en la que vivían sus lectores a partir de propuestas que admitían múltiples interpretaciones.

Uno de los ingredientes más importantes para estimular y dirigir la imaginación infantil es el libroálbum. Pues es allí donde el niño tendrá su primer encuentro con una fantasía estructurada, reflejada en su propia imaginación y animada por sus propios sentimientos. Es donde, con la mediación de un lector adulto, descubrirá la relación con el lenguaje visual y el verbal. Más tarde, cuando esté solo y pase las páginas una y otra vez, las ilustraciones articularán su primer monólogo interior consciente (Lionni, 2003: 20).

Su afición por los animales y su preocupación por hacer llegar a sus lectores en formación una moral y una conciencia ética, enseñar sin desdeñar el valor estético, halló en las fábulas el género adecuado:

Supongo que escribo sobre animales porque me encantan los animales, esa es la razón principal. Y otra razón es que la gente se identifica con facilidad con los animales. Claro que sabemos que los ratones no van al colegio, no beben leche y se visten para las ocasiones especiales, pero es una manera muy fácil y efectiva de decir algo sobre las personas (Random House LLC, 1995-2014).

\footnotetext{
${ }^{1}$ No entraremos en el análisis del álbum, salvo en lo estrictamente necesario y desde un punto de vista descriptivo, puesto que el equipo dirigido por Colomer (2002: 19-36) realizó un exhaustivo estudio del papel que representan las ilustraciones y su relación con el texto.
} 
En su obra puede encontrarse un bestiario que parte del terrario de su infancia al que nos referiremos más abajo: ratones (Frederick, Tili, Matías, Alejandro), lombriz, ranas (Jessica, Marilyn, Augusto), caimán (Cornelius), pájaros Tico), peces (Nadarín), caracoles... que son los protagonistas de sus fábulas, aunque hay una especial predilección por los ratones.

Grosso modo, sin querer sistematizar, las fábulas de Lionni pueden dividirse en dos grandes grupos: el primero, aquel cuyas fábulas tienen su origen en vivencias personales, en recuerdos de la infancia, en personajes que lo acompañaron: «De alguna manera el arte siempre expresa sentimientos de la infancia. Casi siempre lo hace de una manera tan desconcertantemente directa que el artista mismo se impresiona con la fuerza de su presencia e inmediatez» (Lionni, 2003: 17); el segundo, el que recoge la tradición fabulística de transmisión de enseñanzas y valores. En el primer grupo, «[u]n buen libro para niños describe aquellos momentos lejanos de nuestras vidas en los que toda experiencia personal está destinada a ser verdaderamente universal. De manera que un buen libro de niños es, inevitablemente, autobiográfico» (Lionni, 2003: 18). El sueño de Matías, Alejandro y el ratón a cuerda o Frederick -que trataremos detenidamente-son algunos ejemplos de ello. En El sueño de Matías defiende la importancia del artista en la sociedad y el respeto a su individualidad.; en Alejandro y el ratón a cuerda, Lionni muestra su crisis, su lucha entre su mente artística y su mente «mecánica». Los libros son reflejo de sus experiencias. En el segundo grupo, Tili y el muro, plantea la perseverancia en un objetivo y su consecución; Una piedra extraordinaria puede relacionarse con el hipotexto de $E l$ patio feo, de H.C: Andersen y la aceptación de los demás por la sociedad, porque finalmente lo que trasnmite la mayor parte de las fábulas de Lionni es el respeto a la individualidad, en la que la sociedad se transforma, ayuda al protagonista y participa de su éxito.

Sin embargo, para entender la propuesta ética y estética que subyace en Frederick ${ }^{2}$, han de tenerse en cuenta tres circunstancias biográficas que se reflejan en su obra.

[...] los reconocí en las fábulas que he escrito e ilustrado. Entonces me di cuenta de que los protagonistas de mis cuentos eran los mismos pequeños actores silenciosos quienes, durante la etapa de paredes de vidrio de mi infancia, representaron la compleja ficción de casualidad y destino, naturaleza y artificio, vida y muerte. Había ignorado su continua presencia, pero entonces supe cuánto me había condicionado la selección de temas, las preferencias formales, todo el intrincado juego de símbolos que caracterizan mi trabajo como artista (Lionni, 2003: 19).

En primer lugar, su interés por la naturaleza y por los animales que surge en sus terrarios infantiles en los que cobijaba animales vivos: pájaros, peces, tortugas, incluso orugas, en los terrarios que encontraba un refugio: «Eran seguros, predecibles, sustitutos estables de una realidad en permanente movimiento. Eran un refugio del hostil e incierto mundo que me rodeaba» (Lionni, 2003: 20); también destaca en su interés por la naturaleza los paseos con uno de sus tíos por los lagos próximos a Amsterdam; por último, la «fuerte inclinación hacia el estudio de la naturaleza» (Lionni, 2003: 20) en el Colegio de Amsterdam.

\footnotetext{
${ }^{2}$ La edición consultada es la última de Frederick publicada en España por la editorial Kalandraka. Los títulos Frederick ¿Cuándo?, ¿Qué es?, ¿Quién es?, ¿Dónde? son libros con objetivos didácticos que persiguen el conocimiento del entorno del niño.
} 
Fábulas, educación literaria y didáctica de los valores: Leo Lionni

\begin{abstract}
Cuando yo era un niño, era coleccionista apasionado de pequeños animales, sobre todo reptiles. Los guardaba dentro de un terrario que tenía paredes de vidrio donde, con una mezcla de orden y azar, arreglaba arena y piedras, musgo y helechos, para simular un hábitat natural. Con un impresionante sentido de presencia, recuerdo sus formas, colores y olores y, por supuesto, la sorprendente sensación de frío al tacto de los cuerpos resbaladizos de ranas y salamandras, el ritmo rápido de sus pequeños corazones latientes (Lionni, 2003: 19).
\end{abstract}

En segundo lugar, el arte. Desde niño estuvo en contacto con él por medio de sus tíos que potenciaron su creatividad, le hicieron amar la pintura, el ambiente de los talleres. Se familiarizó con los grandes artistas. Visitaba el Rijksmuseum y desde pequeño fue consciente de querer convertirse en un artista. Llegó a estar bajo la influencia del futurismo y fue apoyado por Tomasso Marinetti.

En tercer lugar, el compromiso político que despertó cuando conoció a la italiana Nora Maffi, quien más tarde sería su esposa: su padre fue uno de los fundadores del Partido Comunista Italiano y fue encarcelado por los fascistas. Asimismo, Lionni trabajó con el artista Eduardo Persico, un héroe en los círculos antifascistas que influyó en su escritura y su diseño. Con la llegada del fascismo y la persecución racial, no olvidemos los orígenes judíos de Lionni, optó por emigrar a los Estados Unidos.

Estas tres circunstancias biográficas se reflejan en Frederick: los animales, el arte, el compromiso entendido como necesidad de una ética moral que ayude a dar una visión diferente del mundo.

\footnotetext{
Una familia de ratones recoge provisiones y todos trabajan, excepto Frederick, que aparentemente no hace nada. Pero él también se aprovisiona: rayos de sol, colores, palabras... Cuando llega el invierno, comprueban que su labor poética había sido imprescindible para que los ratones pasen mejor la crudeza de la estación invernal. Así, en este cuento, Frederick es aceptado como es (Kalandraka, 2009).
}

Con este epitexto dirigido a los docentes o a mediadores, la editorial Kalandraka resume en su catálogo la obra de Frederick. En él se hace mención de la visión más amable del protagonista. Sin embargo, Frederick admite distintas lecturas, favorables y desfavorables, que pueden suscitar debates entre los distintos tipos de lector que se acerquen a la obra; es el simbolismo de la fábula, la propuesta estético-literaria, la transmisión de valores sociales, lo que va a coadyuvar al fomento de la creatividad del lector, a su interpretación final.

Frederick es una obra que puede leerse en Educación Infantil, en Educación Primaria o en Educación Secundaria Obligatoria por los distintos niveles de lectura. Frederick se ha convertido en un clásico de la literatura infantil, si bien suele conocerse más entre los prelectores de la Educación Infantil o entre los primeros lectores de Primaria, pero no tanto en los lectores de Secundaria. Frederick es un clásico por su «efecto de resonancia», porque se ubica en una continuidad cultural: «Un clásico es un libro que está antes que otros clásicos; pero quien haya leído primero los otros y después lee aquél, reconoce enseguida su lugar en la genealogía» (Calvino, 2009: 11). En la obra podemos apreciar sus antecedentes, su intemporalidad, los temas universales que plantea y desde el punto de vista de la forma, reconocemos su pertenencia al género fabulístico también por su estructura; a ello, añade las posibilidades que descubre la ilustración. Reúne las condiciones para agradar al «lector ingenuo» y al «lector competente» (Mendoza, 2000: 120-127) e, incluso, facilita al docente el paso de un tipo de lector al otro, según los diferentes niveles de lectura de la obra: el lector ingenuo comienza con una 
lectura superficial del texto; el competente realiza una lectura interpretativa y profundiza en el texto; será su nivel de competencia lingüística, textual y literaria, «de saberes interiorizados relativos a las peculiaridades de las macroestructuras y microestructuras, a las propiedades de las diferentes modalidades de textos y a la amplitud de conocimientos enciclopédicos [las que bastarán] para establecer las relaciones semánticas que conduzcan a la construcción del significado» (Mendoza, 2000: 122). La interpretación, la construcción del significado del texto es el fin de la lectura y en ella confluyen el bagaje intelectual y artístico del lector, sus experiencias de lectura, su conocimiento del mundo y su subjetividad que genera una nueva interpretación del texto. «La clave está en si el lector sabe formularse hipótesis y expectativas y luego las resuelve mediante la aplicación de estrategias y la elaboración de inferencias de comprensión» (Mendoza, 2000: 123).

El título de la obra se centra en el personaje principal de la narración, un ratón llamado Frederick, como otros personajes clásicos -Bambi, Winnie...- En la cubierta, Frederick recibe al lector con una primaveral y poética rosa roja y una sonrisa ladeada; en la contracubierta, lo despide su espalda, el lector es quien ha pasado junto a Frederick que permanece sentado.

Las tapas transmiten la idea de volumen, de que el personaje contiene la historia dentro de sí mismo. Esto es muy pertinente en una historia que trata sobre la creación literaria y sobre la individualidad. Desde la cubierta, Frederick se presenta como un personaje único, su nombre da el título y su imagen enmarca el libro. Las guardas, que contienen el nombre del personaje, extienden su caligrafía por todo el espacio y con ello subrayan esta sensación (Colomer: 2002: 23).

La descripción de la obra comienza con la presentación del hábitat natural de los roedores -una suerte de locus amoenus-, un lugar junto al muro en el que se desarrolla la historia. Después de recolectar para el invierno, en un ambiente primaveral-los colores rojos de los frutos y verde de las hojas contrastan con los colores apagados de las rocas del muro-, Frederick observa las hormigas a sus pies. El narrador afirma que no comparte el trabajo productivo: «Trabajaban todos noche y día. Todos menos uno: Frederick». El trigo vuela sobre las cabezas de los ratones, mientras Frederick permanece de espaldas a ellos y se plantea la pregunta clave para la interpretación de la historia: «iY tú, por qué no trabajas, Frederick?». A lo que responde: «Yo trabajo». Comienza la estructura dialógica y la enumeración de las funciones del trabajo poético que realiza: recoger rayos de sol y palabras para el largo y frío invierno, colores para los días grises. Con la llegada del invierno los ratones, refugiados en el agujero entre las piedras del muro comienzan a contar historias de zorros y gatos tontos, pero la comida empieza a escasear y nadie quiere hablar. « $i \mathrm{Y}$ tus provisiones, Frederick?». La cueva se ilumina y empiezan a aparecer los rayos de sol, los colores, las palabras y el poema de las estaciones: «Tú eres un poeta». Y Frederick entre vanidoso y tímido contesta: «Ya lo sé».

Cañamares propone emplear la estructura tripartita y el «modelo quinario» conjuntamente para analizar la estructura de Frederick:

[...] en la presentación, el estado inicial, sitúa al lector en el viejo muro hecho de piedras en el que se desarrolla la historia y se le presenta a una parlanchina familia de ratoncitos que se afanan en recoger provisiones para el invierno. El inicio del proceso viene contenido en la frase: «Todos trabajaban día y noche. Todos menos Frederick». En el nudo o el proceso los compañeros de Frederick se quejan continuamente porque ese ratoncito no trabaja. Cuando llega el invierno y comienzan a agotarse el calor, la comida y las 
cosas sobre las que hablar, Frederick es quien comparte sus provisiones con ellos: las palabras. Éste sería el cierre del proceso pues se resuelve el problema. Finalmente, en el desenlace, se muestra el resultado ya que todos los ratones creen que Frederick es un poeta, produciéndose el «reconocimiento del héroe» (Cañamares, 2007: 212-213).

A partir de la descripción de la obra, analicemos sus diferentes niveles de lectura para el «lector ingenuo» y el «lector competente». Debemos señalar dos puntos de partida fundamentales: en primer lugar, debe ser el lector quien vaya descubriendo las implicaciones del texto: «explicar los significados o los valores simbólicos de un relato, por ejemplo en la etapa de la educación infantil, equivale a desvirtuar el poder de la ficción, sencillamente, porque o bien se pierde la acción de las estructuras narrativas y psicológicas en el subconsciente, o bien se le está impidiendo al niño la puesta en acción de su capacidad deductiva e imaginativa» (Sánchez Corral (1995: 108). En segundo lugar, la interpretación de los valores dependerá de cada tipo de lector, que será el encargado «de realizar su selección perceptiva dentro del contenido del propio texto basada, fundamentalmente, en sus experiencias, vivencias y aprendizajes con los que se enfrenta al texto que, además, forma parte de su cultura» (Sánchez y Yubero, 2004: 92).

La primera lectura correspondería a un «lector ingenuo», que carece de bagaje lector y de experiencia receptora y que, por lo tanto, no puede establecer y aplicar las necesarias conexiones para la comprensión del texto, un lector que posee un limitado conocimiento de convencionalismos compartidos por el lector respecto al texto, al autor, al grupo cultural y un limitado repertorio (referencias intertextuales, normas socio-históricas, contenido, etc.) ante los requisitos que muestra el texto (Mendoza, 2000: 123). Esta primera lectura llevaría a la lectura literal: un ratón poeta que no colabora con la comunidad, pero que es recibido por ella cuando lo necesita.

La segunda lectura correspondería a un «lector competente»; Frederick como antítesis de la fábula de Esopo La cigarra y la hormiga. Una familia de ratones recoge provisiones para el invierno, salvo Frederick, que en apariencia no realiza ninguna labor para la comunidad, pero también se aprovisiona de rayos de sol, colores, palabras... Con la llegada del invierno, la labor poética de Frederick resulta tan imprescindible como la recolección para que la familia de ratones pueda sobrevivir al invierno. La familia acepta a Frederick tal como es, al contrario de lo que le ocurría a la cigarra de las fábulas clásicas. Lionni le da un nuevo enfoque a la fábula de Esopo y modifica los papeles. Desde el título se produce el cambio: un solo personaje frente a los dos que suelen aparecer en las fábulas tradicionales, lo que evita la oposición que se establece entre ellos. No hay cigarras y hormigas como protagonistas, sino ratones. Solo las hormigas aparecerán en la ilustración como elemento que remite a la fábula clásica, mientras son observadas por Frederick, que interpreta el papel de cigarra mientras los demás trabajan, lo que llevaría a activar el intertex to lector. Esta segunda lectura el «lector competente» va más allá de la descodificación, realiza una interpretación personal, basada en el establecimiento de las conexiones con sus saberes, sus lecturas, hace uso de su competencia literaria y «está dotado de específicos conocimientos previos y experiencias lectoras que le permiten identificar e interpretar legítimamente las referencias textuales, a través de una activa cooperación de su intertexto, en la que intervienen las ineludibles aportaciones de las variables personales» 
(Mendoza, 2000: 123). En esta lectura de Frederick se aprecia la intertextualidad y su antecedente más claro, la fábula de «La cigarra y la hormiga». En Frederick se establece la relación entre el hipertexto y el hipotexto. Si la competencia literaria no es innata, sino que ha de adquirirse y desarrollarse en un proceso de aprendizaje a partir de la propia experiencia, el conocimiento de la fábula clásica será un punto de partida adecuado para el desarrollo de la competencia literaria y el cultivo de la biblioteca personal. Señala De Amo (2005: 75-76) que en Frederick se atisba la parodia y, al mismo tiempo, el travestimiento al utilizar animales humanizados para presentar a los personajes. De esta forma se asegura que el niño se identifique afectiva o humorísticamente con el personaje a la vez que se distancia de él.

Frederick es respetado por su familia que le permite no recoger alimentos para poder cultivar no solo el cuerpo sino también el espíritu de la comunidad. Es un quid pro quo o una suerte de trueque que entronca con la propuesta ética de Lionni: una forma de rebelarse contra una sociedad mercantilista, monocorde, monolítica, que solo reconoce el esfuerzo cuando se refleja en lo material. Frente a ello, destaca la importancia de lo inmaterial, de lo que no produce un bien inmediato visible sino que se refleja en la vida moral de las personas en el cultivo de su imaginación; es necesario el cultivo de la tierra, pero también lo es el cultivo de la mente, del espíritu, de la sensibilidad, de la libertad individual: los ratones respetan la individualidad de Frederick. Hay lugar para una sociedad en la que el poeta, el artista, tienen una función y un compromiso sociales.

El autor elige una fábula que forma parte de la memoria colectiva de una mayoría de los potenciales lectores y su conocimiento les permitirá realizar esta asociación entre el texto clásico y el nuevo texto, esta hipertextualidad en la que retoma «un texto conocido para darle una significación nueva» (De Amo, 2005: 76). Al mismo tiempo, el autor rechaza un código de valores representado por la fábula clásica e incorpora uno nuevo con valores sociales que el lector debe conocer, sabedor de que el la fábula, que siempre ha sido atractiva para niños y para adultos por su sencillez estructural, brevedad y concisión, y el álbum ilustrado, es las forma adecuada para trasnmitirlos.

Si la interpretación que se dio hasta el siglo XIX de la fábula La cigarra y la hormiga de Esopo fue de elogio de la acumulación de riquezas, como consecuencia del trabajo el esfuerzo, la persistencia y la previsión, la glorificación del personaje de la hormiga, el trabajo, como fuente de riqueza material, asociado al sufrimiento que le otorga dignidad, ennoblece y redime al individuo como a la vida caótica, incauta, hedonista y desviada de la norma, que encarna la cigarra (Marreiros, Balça, Azevedo, 2010: 65-66), en adelante «parece que presenta a la cigarra como la buena que canta, es alegre y es divertida, mientras que la hormiga es avarienta. Pero para los cínicos la buena era la hormiga, la hormiga que trabaja. Para el cínico el ponos, el trabajo, es lo encomiable, así como la vida frugal. Y la cigarra que canta y que no trabaja se muere de hambre luego en el invierno: al cínico le parece esto bastante normal. O sea que el sentido era el contrario del posterior. (Rodríguez Adrados, 1994: 144).

Lionni recoge la posición ideológica que comienza a cuestionarse sobre la fábula de La cigarra y la hormiga. Ya desde mediados del siglo XX la propia sociedad ha ido incorporando nuevas versiones 
que conviven con las clásicas ${ }^{3}$. Comienza a reconocerse el papel de la cigarra/artista en la sociedad «al mismo tiempo que se presagia la conciencia de la necesidad de una redistribución de la riqueza, independientemente del tipo de trabajo realizado. Así, la cigarra comienza a emerger como símbolo de un trabajo inmaterial, símbolo de los valores estéticos» (Marreiros, Balça, Azevedo, 2010: 66). Lionni plantea y recoge la ideología y los valores de la sociedad en que nace, pero al mismo tiempo rechaza lo que la fábula clásica representaba. No basta con leerla como lo que la fábula de Frederick aporta sino también por lo que rechaza. No es nueva la aportación de Lionni pero se alía con las versiones que comenzaron a aparecer en el siglo Xx. No reconoce Lionni la importancia de los ratones / hormiga que trabajan hacendosos como único sustento para la sociedad, que entienden el trabajo como recompensa al esfuerzo, sino que plantea un ratón / cigarra que se rebela contra una sociedad preocupada por la riqueza que acaba con toda manifestación artística. Ambos son necesarios para el alimento de la comunidad, el mensaje de Lionni es de convivencia entre ambos, el trabajo intelectual -la cultura- y el trabajo físico, ambos se necesitan y se complementan. Lejos quedan las propuestas clásicas en las que el trabajo físico se identificaba con la esclavitud: «Los filósofos de la antigüedad enseñaban el desprecio al trabajo, esa degradación del hombre libre; los poetas cantaban a la pereza, ese regalo de los dioses» (Lafargue, 2010: 9). Frederick es consciente de que ser poeta es realizar un trabajo cuando lo afirma convencido en la última página. La comunidad respeta el trabajo inmaterial del artista, reconoce el valor estético de su obra y lo acepta. Frente a la fábula clásica, la fábula de Lionni conduce a la aceptación social y a la «métaphorisation d'un savoir social» (Charpentier, 2007: 145)

Para finalizar, una tercera lectura que correspondería al «lector competente»: el egoísmo de Frederick. Las lecturas anteriores nos presentan a Frederick como un personaje consecuente en su reivindicación del trabajo del artista en la sociedad y su contribución al bienestar social, pero aún cabe una interpretación más, la falta de solidaridad de Frederick:

Frederick es un ratón de campo que se niega obstinadamente a ayudar a sus amigos a recolectar comida para el invierno, y que se pasa todo el tiempo componiendo poemas y cuentos. Esa será su contribución. [...] se concentra en sus propias ideas con exclusión de todo lo demás. [...] No es mi intención criticar a Frederick, artista y poeta, pero me asombra que no experimente sentimientos de culpa hacia sus amigos. Está seguro de que seguirán queriéndolo aun cuando se aísle para entregarse a sus pensamientos. Para los adultos, tal lealtad es problemática (Paley, 2006: 21-22).

Esta visión de un Frederick que vive al margen de la sociedad porque es consciente de que al final la sociedad acabará por aceptarlo no suele ser habitual en las interpretaciones sobre la obra de Lionni, de ahí que nos haya parecido interesante añadir esta nueva lectura de una maestra que trabajó en sus aulas de infantil con las obras de Lionni. Los comentarios de algunas de sus alumnas de cinco

\footnotetext{
${ }^{3}$ Vid. «La cigarra y la hormiga» (1934), una de la Silly Symphonies de Walt Disney en la que la cigarra es admitida por las hormigas. En esta línea, a finales del siglo XX, James Finn Garner en sus Más cuentos infantiles políticamente correctos (1996), condena a la hormiga y desprecia el valor material, se destaca a la cigarra, y sus valores, entre otros, de respeto e interculturalidad. En el cine, la magnífica obra de Fernando León de Aranoa Los lunes al sol (2002) muestra una visión crítica de la fábula clásica en edición para niños.
} 
años resultan muy esclarecedoras para las posibilidades que ofrece esa obra en las diversas interpretaciones de los niños:

\footnotetext{
malo.

-Frederick no es bueno como los otros -argumenta Cory, intrigada por el interés de su amiga-. Es

-Eso no es ser malo. [...] Está pensando. De todos modos, los otros es más bueno [sic], pero a mí me gusta Frederick (Paley, 2006: 21-22).
}

Esta visión negativa de un Frederick «malo, tal vez relacionada con la presencia de la pereza de la cigarra como hipotexto o con la no participación en el bien común de la familia, es interpretada por Garralón (2005) desde otro punto de vista: «A muchos Frederick les podrá parecer egoísta, pero el egoísmo del protagonista es, simplemente, una fidelidad consigo mismo que le permite, además, llegar al resto de su comunidad. Sus compañeros de madriguera, lejos de recriminarle, le dejan meditar, respetan su introspección y sienten verdadera curiosidad por su mundo, que, finalmente, agradecen».

Este Frederick, perezoso, ocioso, aparentemente insolidario, individualista, consecuente... refuerza una de las tesis de Lionni: la importancia de la comunidad como suma de individualidades. Es la comunidad la que lo aprecia y lo deja pensar, observar, reflexionar e incluso recitar esos poemas de dudosa calidad. Cambia la respuesta de la sociedad no la del protagonista, es la sociedad la que lo acepta.

\footnotetext{
Quizá el nervio de su pensamiento, el hilo conductor de la mayoría de sus obras sea, con matices, el conocimiento de uno mismo y la aceptación de uno mismo (autoestima). Y después, cuando uno sabe quién es, está en disposición de ayudar a los demás y ser útil a la sociedad (amistad, cooperación). Todo eso nos lo enseña a través del protagonismo humanizado de los animales, especialmente de sus inolvidables ratones, el bicho que más utiliza, con gran diferencia sobre la rana, el pez, la lagartija (Morán, 1984: 55).
}

Como hemos ido viendo Frederick es «una parábola sobre la importancia de la literatura en la vida de los hombres» (Cañamares, 2007: 180), ofrece distintas lecturas según se va desarrollando la competencia literaria del niño. El Frederick de Leo Lionni es un modelo idóneo de literatura para niños, una escritura que admite múltiples lecturas para una época que necesita valores como los que transmite el ratón Frederick y su familia de ratones, basada en una fábula que conocen los niños desde los tiempos de Esopo. Ética y estética confluyen en Frederick, valores sociales y valores artísticoliterarios, formación de los individuos y formación lectora. Despierta sentimientos y plantea interrogantes para diferentes edades. Frederick que permanece en las primeras ilustraciones al margen, acaba convirtiéndose en el protagonista, en el héroe, porque es reconocido por los demás.

Las diferentes lecturas del Frederick de Lionni ofrecen una visión adulta que puede ser comprendida por distintos tipos de lectores según sea su nivel de competencia literaria:

I became ever more conscious of the problems children face and the importance of the messages we send to them. It is often said -and I think somewhat too easily- that to write for children you must be the child, but the opposite is true. In writing for children you must step away and look at the child from the perspective of an adult (Lionni, 1997: 235).

Frederick contribuye a la educación estético-literaria del niño, a establecer las diferentes lecturas que la convierten en una obra para distintos niveles educativos por el acierto en la elección del álbum 
ilustrado y su polifonía, la solución al conflicto planteado que abre nuevas interpretaciones, el simbolismo, la riqueza metafórica de la obra, en suma, contribuye a educar la sensibilidad artística del lector y su conciencia ética.

\section{Referencias bibliográficas}

Calvino, I. (2009): Por qué leer a los clásicos. Madrid, Siruela.

CAÑAmares, C. (2007): Modelos de relatos para «primeros lectores». Cuenca, Ediciones de la Universidad de Castilla-La Mancha, en http://hdl.handle.net/10578/956 (última consulta, 15-82014).

Charpentier, M. C. (2007): «La fable ésopique, littérature de résistence, de soumission ou de subversión de l'ordre social?», Studia Historica, Historia Antigua. 25, pp. 131-146.

COLOMER, T. (1999): Introducción a la literatura infantil. Madrid, Síntesis. , dir. (2002): Siete llaves para valorar las historias infantiles. Madrid, Fundación Germán Sánchez Ruipérez.

De Amo, J. M. (2005): «El papel del álbum en el desarrollo del intertexto lector», Campo Abierto, 28, pp. 61-80.

GARRALÓN, A. (2005): «Clásicos infantiles. Leo Lionni», en http://revistababar.com/wp/clsicosinfantiles-leo-lionni/ (última consulta 15-8-2014).

KALANDRAKA (2009): «Frederick», en http://www.kalandraka.com/blog/wp-content/uploads/2009/ 03/frederick_c.pdf (última consulta, 15-8-2014).

LAfARgue, J. [1880] (2010): El derecho a la pereza. Barcelona, Público.

LionNi, L. (1984): «Antes de las imágenes», Peonza, 65, pp. 16-23. (1997): Between Worlds. New York, Alfred A. Knopf.

LISTA, A. (1859): Colección de trozos escogidos de los mejores hablistas castellanos, en verso y prosa, hecha para el uso de la Casa de Educación, sita en la calle de San Mateo de la Corte, Imprenta de D. Eduardo Hidalgo y Compañía, 1859, en http://www.cervantesvirtual.com/nd/ark:/ $\underline{59851 / b m c c 8285}$ (última consulta 15-8-2014).

LlORENS, R. (1996): «Literatura infantil y valores», Puertas a la lectura, 9-10, pp.95-99.

LLUCH, G. (2003): Análisis de narrativas infantiles y juveniles. Cuenca, Ediciones de la Universidad de Castilla-La Mancha.

MARreiros, S. - BALÇA, A. - AzEVEdo, F. (2010): «“Confabulando” valores: La cigarra y la hormiga», Ocnos, 6, pp. 61-70.

MENDOZA FiLlolA, A. (1996): «El lector ingenuo y el lector competente: pautas para la reflexión sobre la competencia lectora», Puertas a la lectura, 9-10, pp. 120-127.

Morán, J. (1984): «De fábulas, ratones y niños. Recordando a Leo Lionni», Peonza, 65, pp. 52-56.

Paley, V. G. (2006): La niña del lápiz marrón. Buenos Aires, Amorrortu. 
72 Tropelías. Revista de Teoría de la Literatura y Literatura Comparada, 23 (2015)

Ramón F. Llorens García

RANDOM HouSE LLC (1995-2014): Leo Lionni, en http://www.randomhousekids.com/brand/leolionni/ (última consulta, 15-8-2014).

RodríGuez Adrados, F. (1979): Historia de la fábula greco-latina. Madrid, Ediciones de la Universidad Complutense, vol. I.

(1994): «La fábula en Horacio y su poesía», Myrtia, 19, pp. 131-151.

SÁNCHEZ CORRAL, L. (1995): Literatura y lenguaje literario. Barcelona, Paidós.

SÁNCHEZ, S., y YUBERO, S. (2004): «La transmisión y recepción de valores desde la lectura. Un estudio con niños de educación primaria», en Yubero, S. - LARrañaga. E. - CERriLlo, P., coords., Valores y lectura. Estudios multidisciplinares, Cuenca, Ediciones de la Universidad de CastillaLa Mancha, pp. 89-129.

TEJERINA, I. (2000): «Literatura y compromiso: hacer preguntas para buscar respuestas», Puertas a la lectura, 9-10, pp. 180-186.

(2008): «Coordenadas teóricas y contextuales de la educación literaria ante el desafío intercultural», en GRUPO DE INVESTIGACIÓN LAZARILLO, Leer la interculturalidad. Santander, Universidad de Cantabria-Gobierno de Cantabria, pp. 38-87.

TEJERINA, I. - ECHEVARRÍA, E. (2007): «Formación del lector y educación en valores: estética y ética de la literatura», en CERriLlo, P. - CAÑAMARES, C. - SÁNCHEZ, C., coords., Literatura infantil: nuevas lecturas, nuevos lectores. Cuenca, Ediciones de la Universidad de Castilla-La Mancha, pp. 269-278. 